\title{
CORRECTION
}

\section{Correction to: Neue Beobachtungen über Chloridbildungen mittels Thionylchlorid}

Hans Meyer ${ }^{1}$

Published online: 25 June 2021

(c) Springer-Verlag GmbH Austria, part of Springer Nature 2021
Publisher's Note Springer Nature remains neutral with regard to jurisdictional claims in published maps and institutional affiliations.

Leider wurde der Beitrag "Neue Beobachtungen über Chloridbildungen mittels Thionylchlorid" in den folgenden Heften mit unterschiedlichen DOIs veröffentlicht:

1. Volume 22, pages 777-802 (1901)

2. Volume 32, pages 777-802 (1911)

Wir bitten den Fehler zu entschuldigen.

\section{Hans Meyer}

Christiane.brox@springer.com

1 k. k. Deutschen Universität, Prague, Czech Republic 